University of Wollongong

Research Online

Faculty of Engineering and Information

Faculty of Engineering and Information

Sciences - Papers: Part B

Sciences

2018

\title{
Analysis of sintering and bonding of ultrafine WC powder and stainless steel by hot compaction diffusion bonding
}

Mahadi Hasan

University of Wollongong, mh001@uowmail.edu.au

Jingwei Zhao

University of Wollongong, jzhao@uow.edu.au

Zhenyi Huang

Anhui University of Science \& Technology

Li Chang

University of Sydney

Haoruo Zhou

University of Sydney

See next page for additional authors

Follow this and additional works at: https://ro.uow.edu.au/eispapers1

Part of the Engineering Commons, and the Science and Technology Studies Commons

Research Online is the open access institutional repository for the University of Wollongong. For further information contact the UOW Library: research-pubs@uow.edu.au 


\title{
Analysis of sintering and bonding of ultrafine WC powder and stainless steel by hot compaction diffusion bonding
}

\author{
Abstract \\ Bonding between tungsten carbide and steel is a challenging task due to their large difference of physical \\ properties. Previous reports were based on solid state bonding. In this study, a powder-solid mechanism \\ was employed for analysing the sintering and bonding process of ultrafine WC (with $8 \%$ Co added as \\ binder) powder and solid stainless steel (SS 304). A novel manufacturing mechanism of hot compaction \\ diffusion bonding (HCDB) was implemented to facilitate the bonding process. The influence of \\ temperature varying from 1160 to $1220^{\circ} \mathrm{C}$ was investigated with an interval of $20^{\circ} \mathrm{C}$. The experiment is \\ conducted in a vacuum environment at constant pressure of $160 \mathrm{MPa}$. Under simultaneous effects of \\ temperature and pressure, WC powder was solidified and a diffusion bonding was realised with SS 304 . \\ The bonding interface is characterised by three distinctive features, namely properly bonded area, crack \\ appearance and formation of diffusion layer. Generation of micro cracks are examined in the form of \\ single long micro crack, cluster of micro cracks and crack in WC region. An average hardness of $1971 \mathrm{HV}$ \\ was found at $1220^{\circ} \mathrm{C}$, and the maximum mechanical bonding shear strength achieved was $172 \mathrm{MPa}$. The \\ microstructure morphology, composition distribution, bonding characteristics and crack formation, \\ diffusion mechanism and mechanical properties of the composite bimetal were examined. The fabricated \\ composite bimetal has the potentials in the applications where high hardness and high strength are \\ required simultaneously.

\section{Disciplines} \\ Engineering | Science and Technology Studies

\section{Publication Details} \\ Hasan, M., Zhao, J., Huang, Z., Chang, L., Zhou, H. \& Jiang, Z. (2018). Analysis of sintering and bonding of \\ ultrafine WC powder and stainless steel by hot compaction diffusion bonding. Fusion Engineering and \\ Design, 133 39-50.
}

\section{Authors}

Mahadi Hasan, Jingwei Zhao, Zhenyi Huang, Li Chang, Haoruo Zhou, and Zhengyi Jiang 


\title{
ANALYSIS OF SINTERING AND BONDING OF ULTRAFINE WC POWDER AND STAINLESS STEEL BY HOT COMPACTION DIFFUSION BONDING
}

\author{
Mahadi Hasan, Jingwei Zhao, Huang Zhenyi, Li Chang, Haoruo Zhou, Zhengyi Jiang*
}

\begin{abstract}
:
Bonding between tungsten and steel is a challenging task due to their large difference of physical properties. Previous reports were based on solid state bonding. In this study, a powder-solid mechanism was employed for analysing the sintering and bonding process of ultrafine WC powder and solid stainless steel (SS 304). A novel manufacturing mechanism of hot compaction diffusion bonding (HCDB) was implemented to facilitate the bonding process. The influence of temperature varying from $1160-1220^{\circ} \mathrm{C}$ was investigated with an interval of $20^{\circ} \mathrm{C}$. The experiment is conducted in a vacuum environment at constant pressure of $160 \mathrm{MPa}$. Under simultaneous effects of temperature and pressure, WC powder was completely solidifiedand a diffusion bonding was realised with SS 304 . The microstructure, composition distribution, bonding characteristics and mechanical properties of the composite bimetal were examined. The fabricated composite bimetal has potentials in the applications where high hardness and high strength are required simultaneously.
\end{abstract}

Keywords: Composite bimetal, Powder-Solid joining, Diffusion, $\mathrm{HCDB}$, bonding temperature.

*Corresponding author. Tel: +61-2-42214545; Fax: +61-2-42215474

E-mail addresses: mh001@uowmail.edu.au (M. Hasan), jwzhaocn@gmail.com (J. Zhao), jiang@uow.edu.au (Z. Jiang) 


\section{Introduction:}

Over the last few decades, tungsten carbide (WC) materials have been widely used in many industries such as micro drills, nuclear refractory parts, medical equipments, due to their attractive properties which includes high hardness, high melting point, high density and high wear and erosion resistance[1-3]. The WC materials, however, are essentially brittle as well as expensive that shrink its applications to a limited area. Because of brittleness behaviour, components made from WC may fail with a tiny distortion. Especially in the applications like precision micro drilling, a little misalignment of the machine and micro drill, or a slight increase in thrust force may cause the micro drill to break, resulting in the loss of not only the tools but also the work piece. Similarly, in nuclear fusion plant, W is used as plasma facing material subjected to a very high surface erosion and heat load, requiring an essential high strength material to support the component structure $[4,5]$. Therefore, substituting a portion of WC components by a material of higher strength and fracture toughness (for example steel) could solve these problems. A composite bimetal structure of outer material WC can provide adequate hardness and wear resistance and the inner high strength material can prevent the breakage. As a result, developing such WC/steel composite structure is of great importance in terms of component durability and cost.

Fabricating such composite material, however, is restricted by a number of factors in relation to the large difference of their physical properties and the fabrication methods. For instance, the big differences of their melting points $\left(\sim 2800^{\circ} \mathrm{C}\right.$ for $\mathrm{WC}$ and $\sim 1500^{\circ} \mathrm{C}$ for steel depending on alloying elements used) has made the joining process difficult. The key issue of $\mathrm{WC} /$ steel bonding is the huge mismatch of their coefficient of thermal expansion (CTE), which is $4.5 \times 10^{-6} \mathrm{~K}-1$ for tungsten and $12 \times 10^{-6} \mathrm{~K}-1$ for steel. This difference causes high thermally induced residual stresses trapped at the interface of bonding when the joint materials are cooled down from the bonding temperature to atmospheric temperature. It results in a reduction of tensile strength and toughness of the joint, leading to the crack, delamination and decreasing the service life of the components $[6,7]$.

Afew research works have been reported to combine $W$ or WC with various types of alloying steels by means of a number of different techniques that include conventional welding, metal brazing [8], plasma spraying [9], spark plasma sintering [10], pulse plasma sintering [7, 11], and diffusion bonding $[12,13]$. In order to compensate the big difference of CTE between WC and steel, a solution used by some researchers is employing an interlayer in the middle of two materials, whose CTE falls in between WC and steel. Zhong et al. [13] used a titanium interlayer to bond tungsten with $\mathrm{F} 82 \mathrm{H}$ steel by diffusion bonding. A nickel layer was used by Zhong et al. [14], to create the bonding between the tungsten and ferritic steel under vacuum condition at $900^{\circ} \mathrm{C}$ for $0.5-2 \mathrm{~h}$. Rosinski et al. [7] applied a pulse plasma sintering (PPS) method to combine tungsten rods with Eurofer 97 steel by employing four different types of interlayer i.e., Fe, 86FeTi, Ti and 25FeTi. Feng et al. [15] has joined WC-Co with 410 type stainless steel by diffusion bonding with a $\mathrm{Ni}$ interlayer. Yang et al. [12] studied the diffusion bonding of tungsten and stainless steel by using an interlayer made of $\mathrm{Cu}, \mathrm{W}$ and $\mathrm{Ni}$, in a vacuum environment at $1150^{\circ} \mathrm{C}$ with a pressure of 5 $\mathrm{MPa}$ for $60 \mathrm{~min}$. All these methods mentioned above are solid state joining of WC and steel, mostly with the aid of an interlayer.Solid state joining, however, is not suitable for complex shape parts. It also requires the parts to be made in an accurate shape prior to undergoing the joining process which leads the process to be less prone in practical applications point of view.In addition, thedependency on a third material as an interlayer leads to furtherprocess intricacy. Furthermore, most of the existing research have been focused on the fabrication of macrosize parts. When the processed parts are scaled down, problems in designing the experimental die set-up, fabrication method and system for mechanical properties analysis may appear, which challenge the successful bonding of composite parts.

In this study, a novelpowder/solid hot diffusion compaction bonding technique to join WC powder with thin stainless steel (SS304) wire under dual action of heating and pressurizing has been demonstrated. The technique simultaneously solidifies the WC powder as well as making a bonding with steelwirewithout the aid of an interlayer. A Gleeble-3500 thermomechanical simulator was employed in order to conduct the bonding experiment by means of electrical resistance heating and pressing technique. A special arrangement of die setup was designed and fabricated in order to fit in Gleeble-3500 and conduct the experiments of producing small sized composite parts. 
The microstructures and compositions of the sintered WC as well as bonding interface were investigated. The mechanical properties of the fabricated joints were analysed. In the applications where high hardness and high strength are required concurrently such as divertor of nuclear fusion power plants and composite micro drill; the fabricated composite bimetal can contribute significantly.

\section{Hot Compaction Diffusion Bonding (HCDB)}

A number of different approaches for the consolidation of nanostructured WC-Co powder have been reported in the past. These include liquid phase sintering (LPS) $[16,17]$, hot isostatic pressing (HIP) [18], spark plasma sintering (SPS) [19, 20], pulse plasma sintering (PPS) [21], high frequency induction heated sintering (HFIHS) [22], and rapid Omni compaction (ROC) [23]. A comparison of all these approaches can be found elsewhere in [24]. These processes require high sintering temperature and long time to achieve full/near density of the product. High temperature leads to rapid grain growth of the powder, causing coarsen microstructure and eventually degrading the mechanical properties of the processed parts. A good alternative is to use an electrical resistance based sintering technique, which has the advantages of high density achievement, enhanced sintering kinetics, minimum sensitivity to initial powder preparation, strong inter-particle bonding, and improved final microstructure [25]. In the past a few electrical resistance based techniques for the consolidation of metal powders have been reported, however, limited to solidifying a single metal powder such as Ti powder[26], and metal matrix composite[27], and cast iron[28]. In this study a simultaneous effect of pressure and resistance heating is utilized in order to perform sintering of ultrafine powder and diffusion bonding between WC and thin steel wireconcurrently.

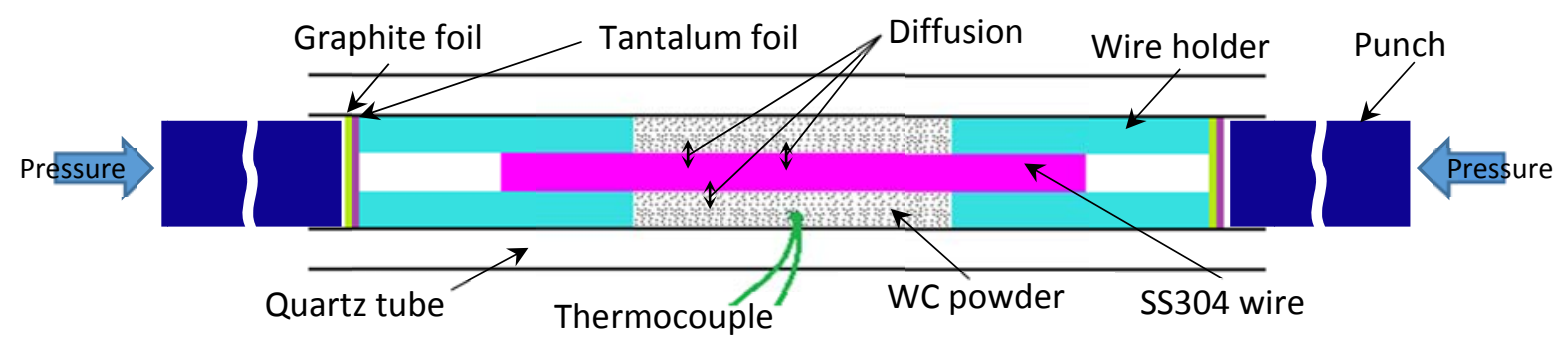

Fig. 1 Schematic diagram of hot compaction diffusion bonding

A novel approach, namely hot diffusion compaction bonding (HCDB), has been implemented in this study in order to investigate the powder-solid diffusion bonding. The schematic diagram of HCDB is presented in Fig. 1. HCDB is based on the principle of electrical resistance sintering. In addition a pressure is employed instantaneously to accelerate the densification process. In this method, electrically conductive samples (WC powder as core material and SS304wire as sleeve material) areplaced in an insulated container/die (quartz tube in this experiment). Electrical current is then flowed from one end to the other end through the sample and generate resistance heating by means of Joule effect. Single or multiple pulses current are supplied in order to propagate rapid inter-particle as well as diffusion bonding between two materials. Consequently, a continuous pressure from both sides of the sample helps to quicken the compaction of the powder as well as bonding between two materials. Therefore, HCDB has a potential to produce fine grain, uniform and full/near full density of the final product in a short time.

\section{Experimental procedure}

In this study, near spherical-shaped plasma arc discharged ultrafine WC powders with an average particle size (APS) of $400 \mathrm{~nm}$ were used as outer sleeve material andaustenitic SS 304 wire of $1 \mathrm{~mm}$ diameter was used as inner core material. The chemical compositions of WC-8Co powder and SS 304 are presented in Table 1. The scanning electron microscope (SEM) image and energy dispersive spectroscopy (EDS) mapping of the as received powders are shown in Fig. 2. It can be seen (Fig. 2 (a)) that the ultrafine WC-Co powders are fairly uniform with an APS of 400nm particle 
size. Fig. 2(b)- (d) show the presence of W, C and Co particles, respectively. Two phasesWC and WCCoare present, as depicted in phase analysis maps (Fig. 2 (e)-(f)) by Aztec-3.3, Oxford instrument for nano-analysis.

Table 1 Chemical compositions of WC and SS304 (wt \%)

\begin{tabular}{ccccccccccccccc}
\hline Material & $\mathrm{Co}$ & $\mathrm{Fe}$ & $\mathrm{Cr}$ & $\mathrm{N}$ & $\mathrm{Ni}$ & $\mathrm{Zn}$ & $\mathrm{Al}$ & $\mathrm{V}$ & $\mathrm{Mn}$ & $\mathrm{C}$ & $\mathrm{O}$ & $\mathrm{P}$ & $\mathrm{S}$ & $\mathrm{Si}$ \\
\hline WC & 8.0 & 0.05 & $<0.01$ & 0.06 & 0.02 & $<0.06$ & 0.03 & 0.04 & - & - & $<0.5$ & - & - & - \\
SS304 & - & Balance & $<19.5$ & $<0.1$ & $<10.5$ & & & & 2.0 & $<0.08$ & - & 0.045 & 0.03 & 0.75 \\
\hline
\end{tabular}
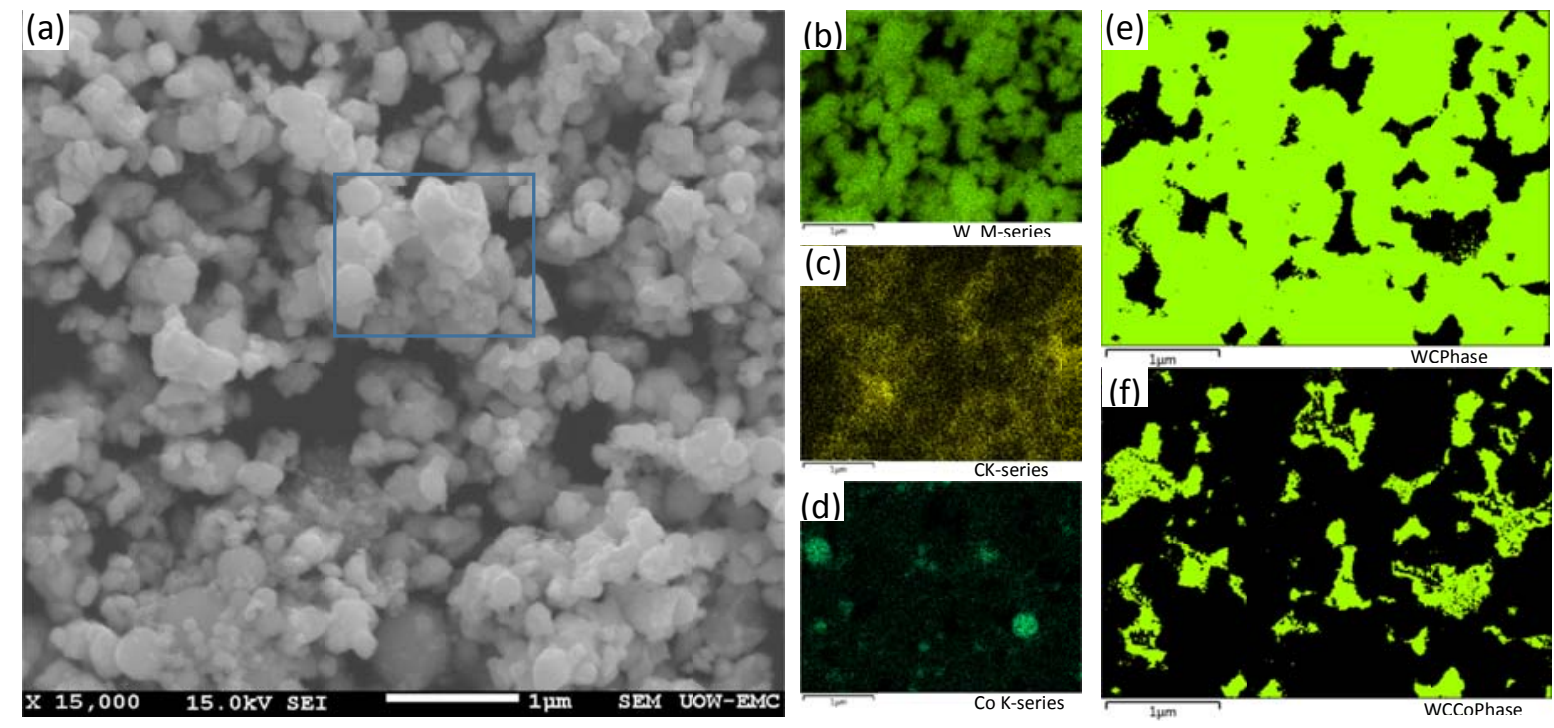

Fig. 2(a) SEM image and $(b-f)$ EDS mapping of the as-received WC-8Co powders.

In order to conduct the sintering and bonding experiment, Gleeble-3500 thermomechanical simulator was used. The Gleeble 3500 (Fig. 3 (a) and (b)) is equipped with a fully integrated digital closed loop control thermal and mechanical testing system, which can provide an accurate execution and repeatable testing programs. The machine typically has a high speed resistance heating system, a servo hydraulic pressurizing system and a computer based data acquisition system and is suitable for various processes such as hot rolling, continuous casting, forging, welding and extrusion[29]. The experimental arrangements are presented in Fig. 3 (c) and (d). As shown in the exploded view designed in Solidworks (Fig. 3 (c)), the wire-holder was first inserted into the quartz tube of inside diameter (ID) $2.7 \mathrm{~mm}$ and outside diameter (OD) $6 \mathrm{~mm}$ and length $50 \mathrm{~mm}$. One millimetre diameter SS304wire was then inserted into the wire holder up to a distance of $4 \mathrm{~mm}$. Afterwards, ultrafine WC powder was poured inside the quartz tube. The powder was then compacted under the manual pressure to a green density of approximately $13 \%$. Achieving of higher green density was restricted due to the possibility of the breakage of the quartz tube. After manual compression, the second wire-holder was inserted to the other side of the quartz tube. A thin layer of tantalum foil was placed on the end of wire holder, followed by graphite foil in order to protect the punch not to adhere with the wire holder, as shown in Fig. 1. A pair of thermocouples was used to control the machine's functionality during experiment. They were inserted through a $1 \mathrm{~mm}$ hole made through the wall of quartz tube. Portion of thermocouples that passed inside die were insulated by ceramic tubes. The prepared sample was then placed inside the die set-up, and assembled by four screws and then placed inside Gleeble- 3500 simulator and clamped between the two jaws as shown in Fig. 3 (b).Gleeble-3500 jaws were adjusted to hold the punch guides and moved smoothly on horizontal axis and then subjected to conduct hot compression in a vacuum environment $\left(<5.0 \times 10^{-3} \mathrm{Torr}\right)$. Prior to assembling all the components were cleaned in an ultrasonic bath using ethanol for 10 mins and then dried in air. 

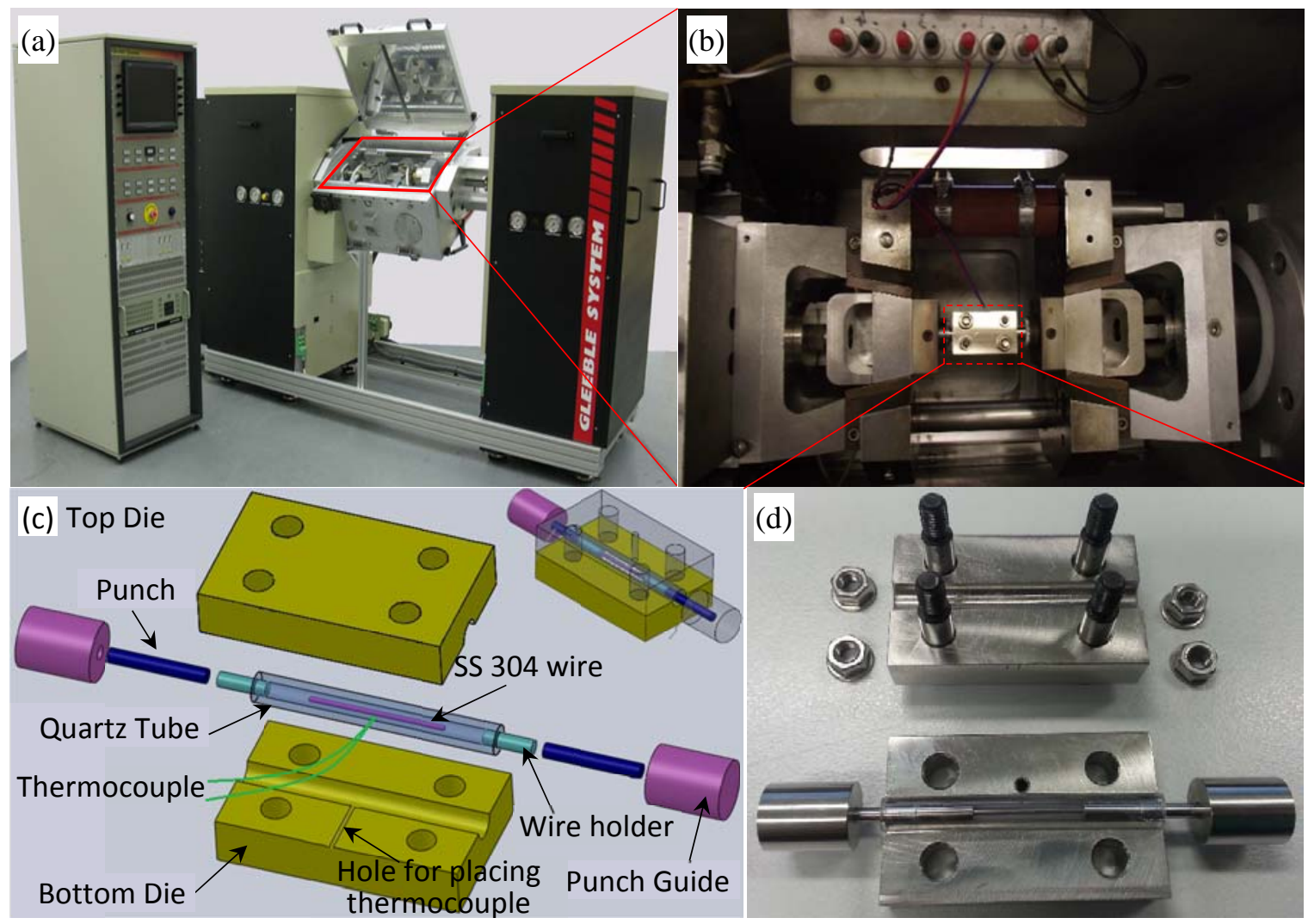

Fig. 3Sintering and bonding experiment setup:(a) Gleeble 3500 thermomechanical simulator, (b) Illustration of compression system, (c) exploded view of die assembly, designed in Solidworks, and (d) die assembly fitted inside Gleeble-3500.

The experiment was carried out in vacuum environment. Thetemperature range used in this study was varied from $1160-1220^{\circ} \mathrm{C}$ with an interval of $20^{\circ} \mathrm{C}$. A constant pressure of $160 \mathrm{MPa}$ was employed throughout the experiment for 20 min of sintering time. Fig. 4(a) and (b) show the history of sintering and bonding process of HCDB conducted in Gleeble-3500 simulator. A slow heating and cooling rate of $2^{\circ} \mathrm{C} / \mathrm{s}$ was implemented in order to achieve full/near full density of the WC and better quality of the bonding as shown in Fig. 4 9(a).Fig. 4 (b) shows the history of compactionstroke movement. The powder compaction range varied from 12-15 mm depending upon the temperature. A maximum of $15 \mathrm{~mm}$ powder compaction was obtained at $1220^{\circ} \mathrm{C}$.
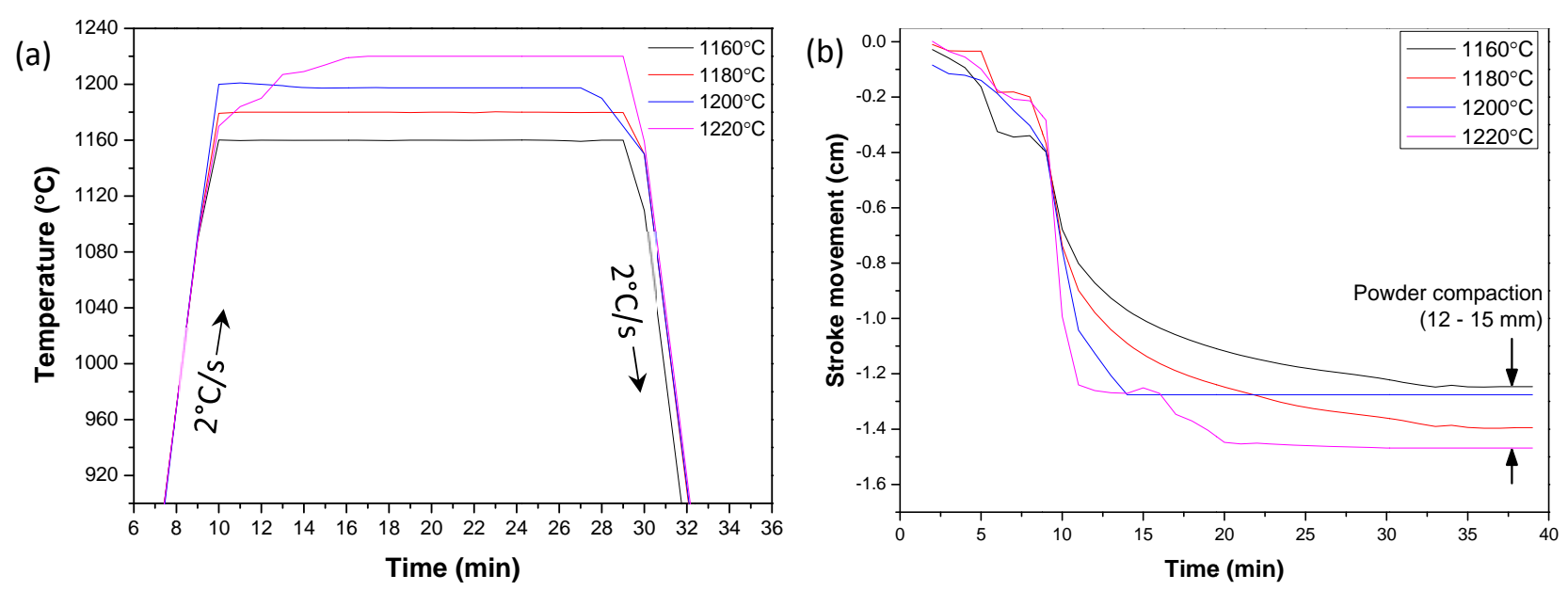
Fig. 4History of hot compression processat different temperatures:(a) heating and cooling, and(b) stroke movement.

To examine the microstructure and bonding quality of the composite bimetal, specimens were prepared by cutting the cross section of the bimetal across Y-Z plane as shown in Fig. 5 (a). The specimens were then mounted in $20 \mathrm{ml}$ of polyfast resin by Citopress Mounting Press machine (Struers) followed by grinding and polishing to $1 \mu \mathrm{m}$ diamond finish by Tegramin grinding \& polishing machine (Struers). The microstructure of sintered WC and bonding were analysed by SEM equipped with backscattered electron (BE) and EDS. The grain and grain size distribution were analysed by optical microscope (OM) and the images were processed by Leica Application suite(LAS Core V4.0) software to create the histogram. The phases of the fabricated composite bimetal were examined by $\mathrm{X}$-ray diffractometer (XRD) using monochromated Cu Ka radiation.

The mechanical properties of bimetal were evaluated by examining the microhardness and bonding shear strength at room temperature. The micro hardness profiles were obtained across the interface of the bonded area by StruersDurascan Vickers microhardness tester using $0.5 \mathrm{~kg}$ load and 10 seconds dwell time. A tailor made testing setup was designed to carry out bonding shear strength test. The schematic diagram of the arrangement is presented in Fig. 5 (b). The specimens were cut by precision cutting machine with a thickness of $0.7 \mathrm{~mm}$, and tensile tests were conducted on a micro tensile testing machine.The bonding zone were examined using SEM and the bonding shear strength was calculated using Eq. (1).

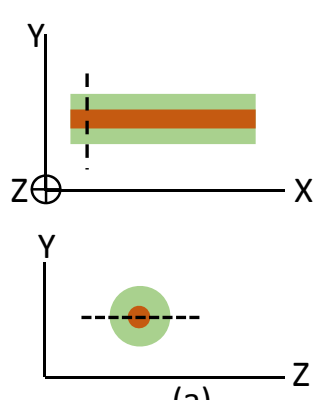

(a)
Right bracket to micro

tensile testing machine $\rightarrow \ll 0.7 \mathrm{~mm}$

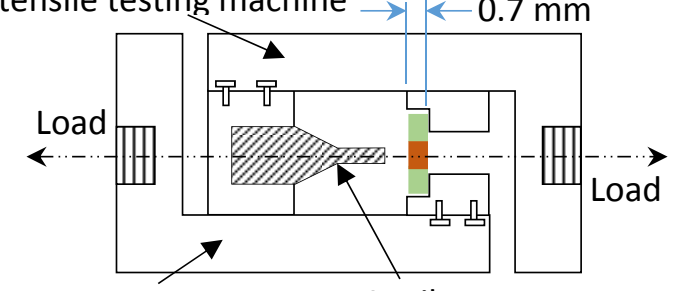

Left bracket to micro Anvil

tensile testing machine

(b)

Fig. 5 Schematic of mechanical properties testing (a) schematic of cutting views,(b) bonding shear strength test.

$\sigma_{\text {bonding }}=\frac{F_{\text {maximum }}}{A_{\text {bonding }}}$

where $\sigma_{\text {bonding }}$ is the shear bonding strength in $\mathrm{MPa}, F_{\text {maximum }}$ is the maximum load recorded in micro tensile testing machine in $\mathrm{N}$, and $A_{\text {bonding }}$ is the shear bonding area in $\mathrm{m}^{2}$.

\section{Results and Discussion:}

\subsection{Microstructures of sintered WC powder and SS304 under HCDB}

Fig. 6 shows the density and SEM micrograph of the sintered WC ultrafine powder. Fig. 6 (a) indicates that density increases with the increment of temperature while the applied pressure and sintering time are kept constant, and the maximum density of $84.40 \%$ is achieved when the sintering temperature is increased to $1220{ }^{\circ} \mathrm{C}$. The achievement of full density is limited by the initial small green density of $12-15 \%$ when compared to theoretical density. This is because the green density was obtained by manual pressing of WC inside the quartz tube considering the possibility of cracking the quartz tube at high pressure. Fig. 6 (b) - (d) show the microstructure of sintered WC powder at different temperatures. It can be seen that the inter-particle gaps decreases with the increase of temperature, indicating that the density of sintered powder is dependent on the temperature applied as reported in [30]. This is due to the fact that grains of WC powders grows bigger with the temperature. This 
phenomenon is explained by Wang et al. [31], and shown that the grain growth of WC powder is a function of temperature and time. Similar findings were also observed in this experiment that the grain growth occurred with the increment of temperature which eventually contributed to the increase of the density as shown in Fig. 6(a).
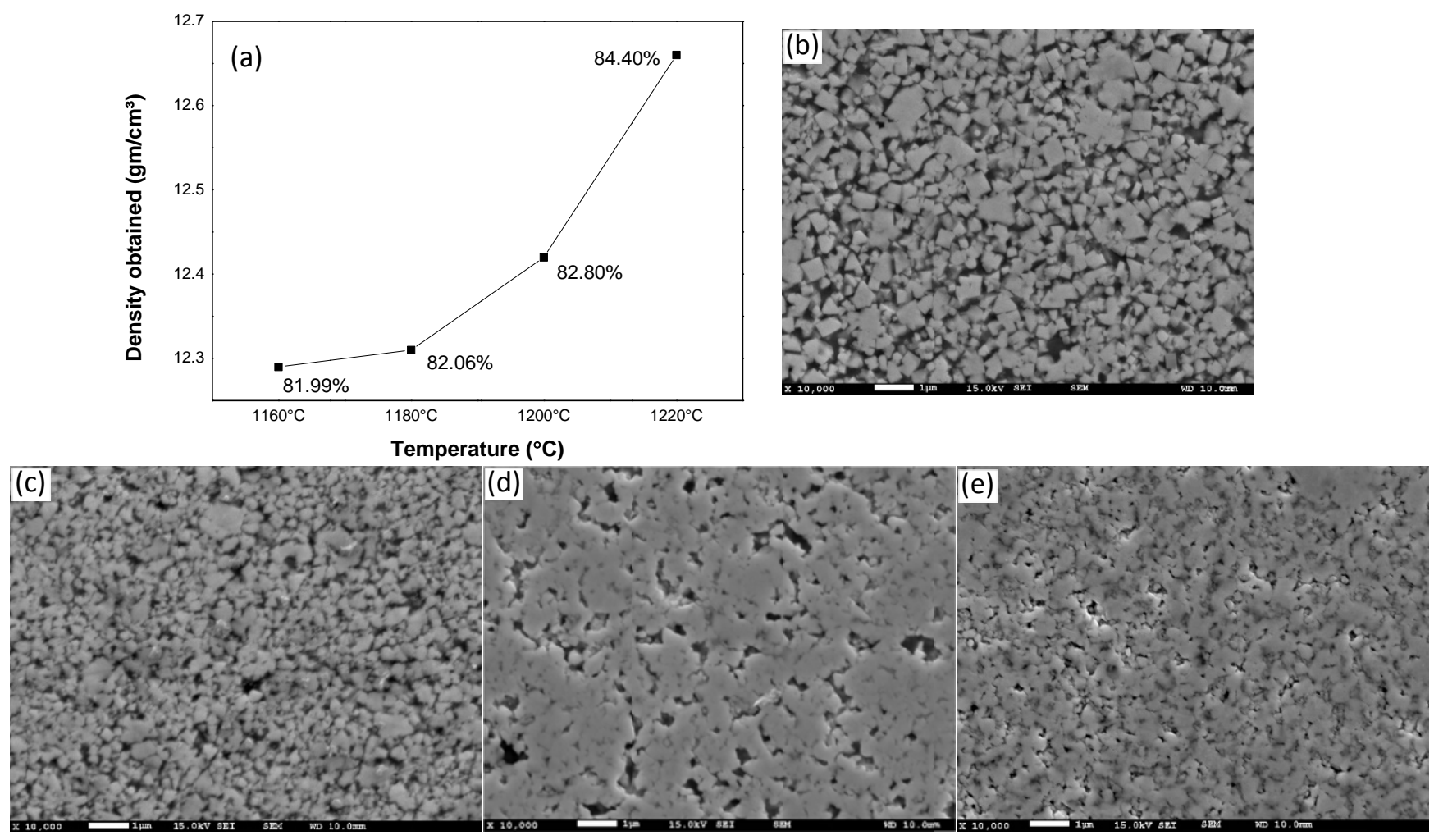

Fig. 6(a)Dependence of density of sintered WC powder on temperature, and microstructure sintered at (b) $1160^{\circ} \mathrm{C}$, (c) $1180^{\circ} \mathrm{C}$, (d) $1200^{\circ} \mathrm{C}$, and(e) $1220^{\circ} \mathrm{C}$

Fig. 7 presents the EDS mapping of the WC powder sintered at $1220^{\circ} \mathrm{C}$. The SEM image is taken from the solidified area of WC away from SS304. It can be seen that all the alloying elements distribute spatially. For analysing the grains and grain size distribution, the specimens were examined under OM. As shown in Fig. 8 (a), the average grain size obtained for SS304 is $83.9 \mu \mathrm{m}$, with the maximum grain size of $176 \mu \mathrm{m}$. The grain sizes of SS 304 at different temperatures are nearly the same. Fig. 8 (b) shows the grain size distribution of SS304 obtained at $1220^{\circ} \mathrm{C}$. It can be seen that the results are similar to the work investigated by Bialobrzeska et al. [32].They have examined that the grain size of austenitic steel with holding time of $20 \mathrm{~min}$ at $1200{ }^{\circ} \mathrm{C}$ ranges from $79 \mu \mathrm{m}-270 \mu \mathrm{m}$. Though the average grain size obtained in this experiment falls in their range, but the formation of very big size grain is restricted by diminutive dimension of the specimen. The average grain size obtained for the WC sintered at $1220^{\circ} \mathrm{C}$ is $271 \mathrm{~nm}$, with the maximum value of $543.3 \mathrm{~nm}$ as shown in Fig. 8(c). It can be seen from the figure that identification of boundaries of all grain is difficult, due to which grains with clear boundaries are considered for determining the grain size distribution as presented in Fig. 8(d). Sun et al. [33] investigated that the grain size of WC-Co powder and have found that, between temperatures of 1160 to $1220^{\circ} \mathrm{C}$, the grain size ranges from 250 to $420 \mathrm{~nm}$.In our observation the grain size achieved is slightly higher than their investigation. This grain growth is caused due to simultaneous of effect of heating and pressing at high pressure. 

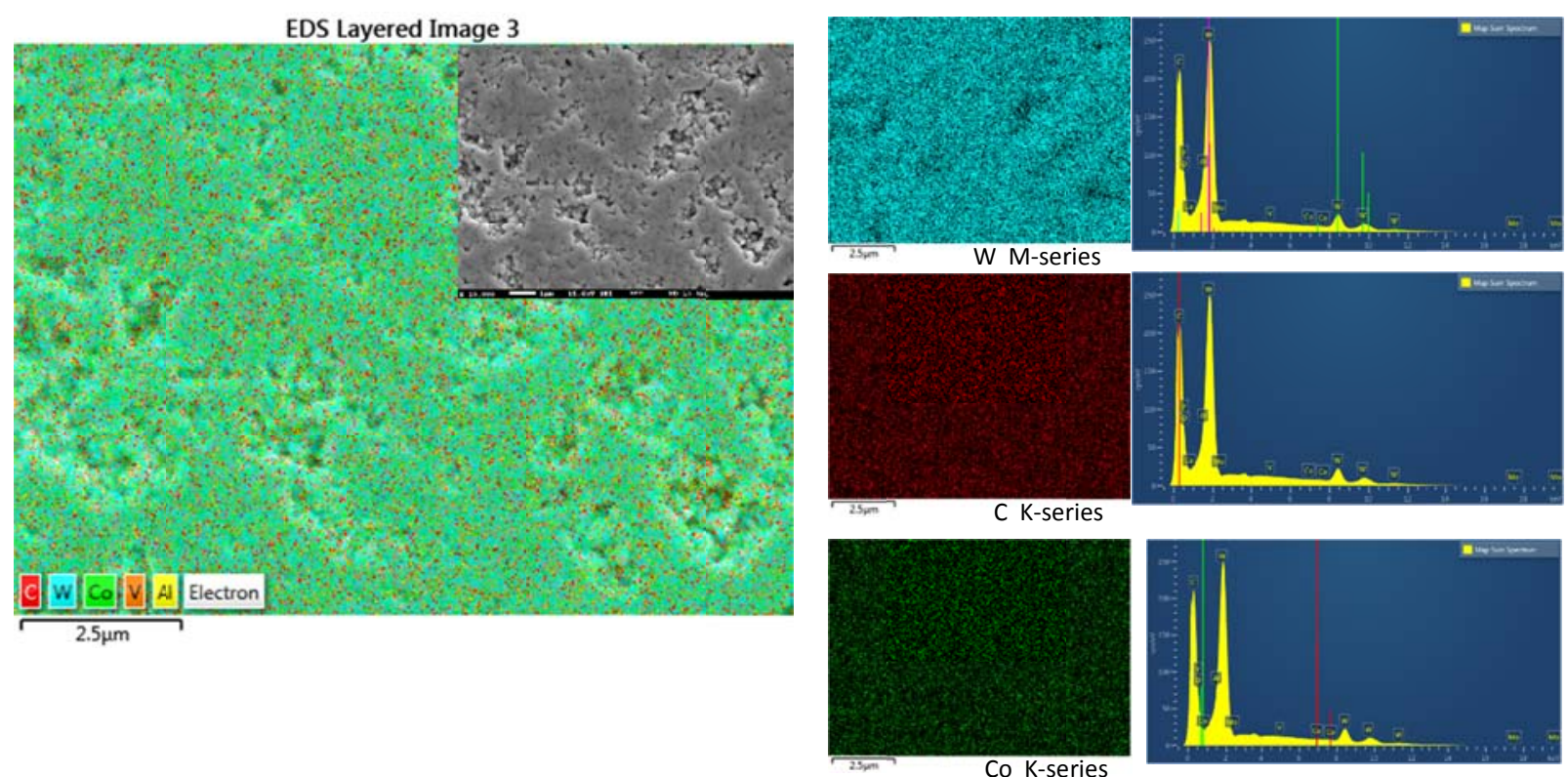

Fig. 7EDS mapping of the WC powder sintered at $1220^{\circ} \mathrm{C}$.
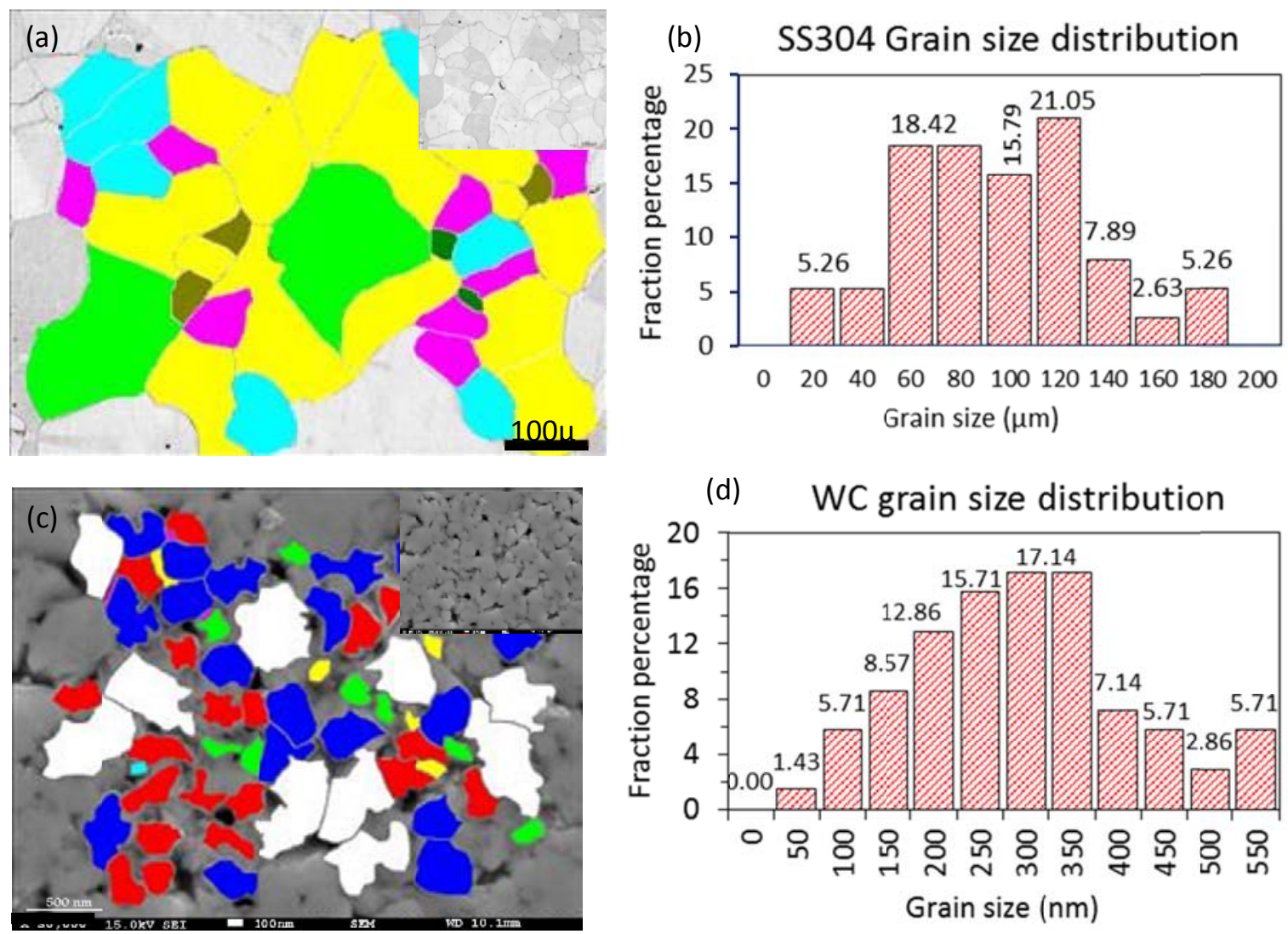
Fig. 8 Grain boundaries and grain size distribution of(a, b) SS304, and (c, d) WC sintered at $1220^{\circ} \mathrm{C}$.

\subsection{Microstructure and morphology of the bonding interface}

The bonding between WC and SS304 is characterised by three phenomena. Firstly, the region of successful bonding, secondly the appearance of crack at the interface and lastly the formation of an interface layer at the joining area. Fig. 9 shows the BE SEM micrographs (left side) and EDS mapping (right side) of the joint interface bonded at different temperatures. All images are taken under same magnification for comparison. In all the BE images, the left or bottom part with light grey contrast is WC and the right or upper part with deep grey contrast is SS304. All the bonding interfaces present similar layered microstructure, however, the diffusion zone grows bigger with the increase of temperature from 1160 to $1220^{\circ} \mathrm{C}$. This indicates that the atomic interdiffusion is augmented at higher temperature. This phenomenon is also observed by Zhong et al. [13] in their investigation of joining W and F82H steel. At $1160^{\circ} \mathrm{C}, \mathrm{WC}$ at the interface is characterized by large amount of micro gaps as shown in Fig. 9(a). It can be seen that the WC is characterized by low density and large amount of micro gaps. This indicates that the densification of WC powder particles does not occur completely at this temperature. The diffusion of small amount of Fe and $\mathrm{Cr}$ into WC area, and Co into steel area is observed, as indicated by EDS mapping. At lower temperatures of $1160^{\circ} \mathrm{C}$ and $1180^{\circ} \mathrm{C}$, no migration of $\mathrm{W}$ element is observed. Migration of $\mathrm{W}$ element is the minimum in all cases, which is thought to be due to the high molecular mass of W,as explained by Pelleg[34] that smaller atoms diffuse more readily and fit into atomic vacancies more easily than that of larger ones. With the increment of temperature, the solidification of WC powder improves. As shown in Fig. 9(b), the quantity of micro gaps has reduced with the increase of temperature from 1160 to $1180{ }^{\circ} \mathrm{C}$. The bonding interface and diffusion features at $1180{ }^{\circ} \mathrm{C}$ remain nearly the same as that at $1160^{\circ} \mathrm{C}$. At temperatures of $1200^{\circ} \mathrm{C}$ and $1220^{\circ} \mathrm{C}$, the diffusion of $\mathrm{Fe}$ and $\mathrm{Cr}$ elements into WC area is significant, as shown in Fig. 9(c) and (d). Diffusion of a small amount of W element into steel zone is also realised at these two temperatures. As shown in Fig. 9(c), the solidification of powder has been improved. At $1220^{\circ} \mathrm{C}$, the highly densified WC is observed with a minimum number of micro gaps, as indicated in Fig. 9(d). The micro gaps are not completely avoided because of the initial loose green compact as discussed in previous section. However, the inter-particle diffusion proves the successful bonding between powder-solid composite bimetal of WC and SS 304. This can also be demonstrated that the diffusion increases with the increase of temperature, so does the improvement of bonding. 

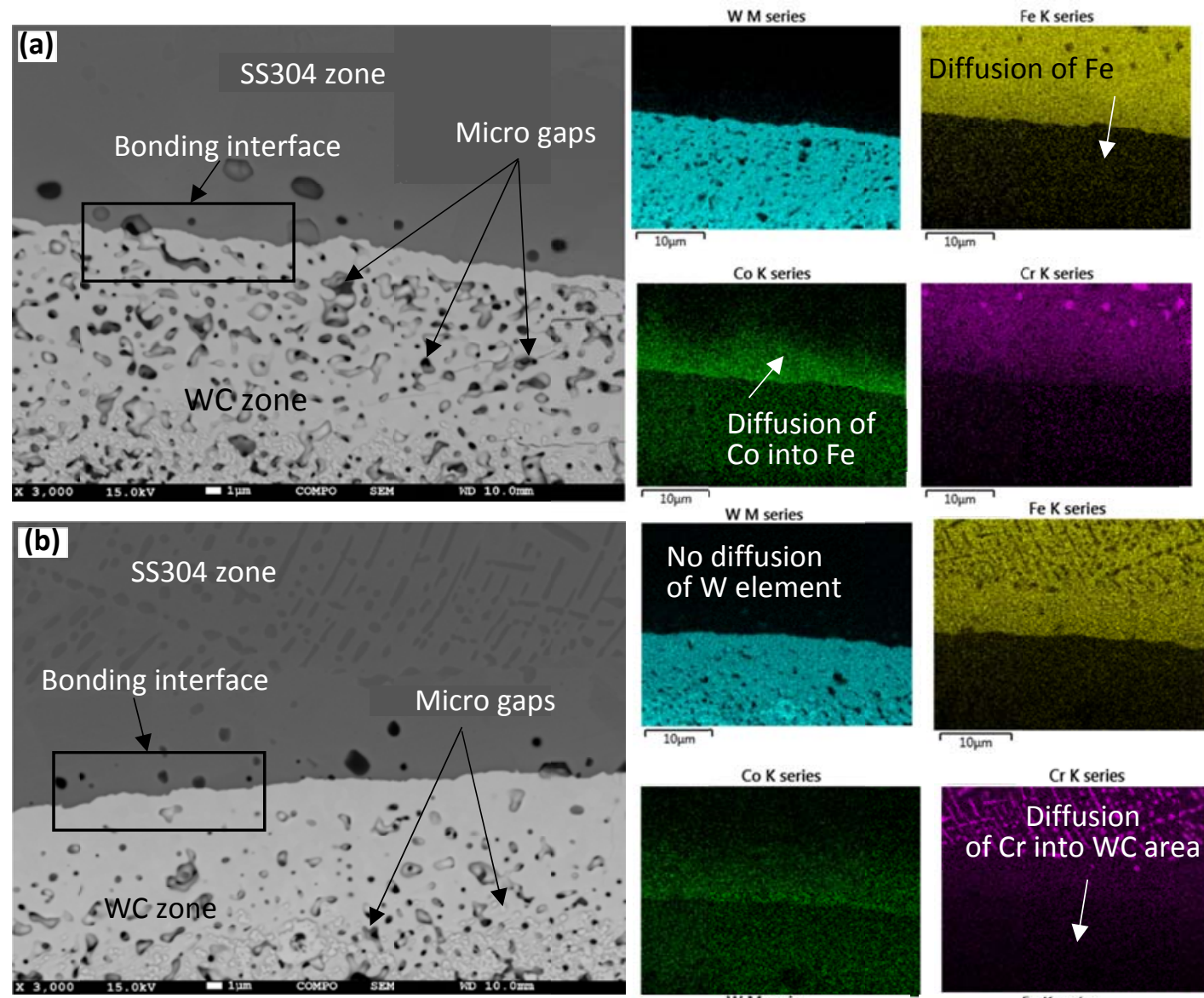

of W element
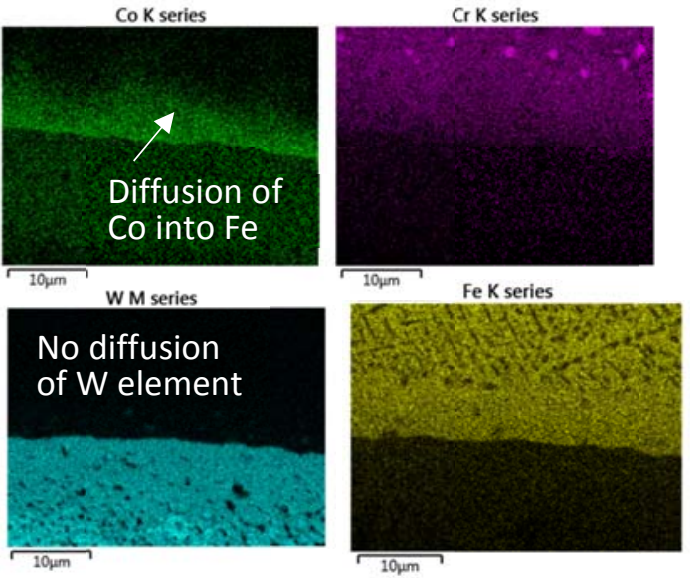

Co K series
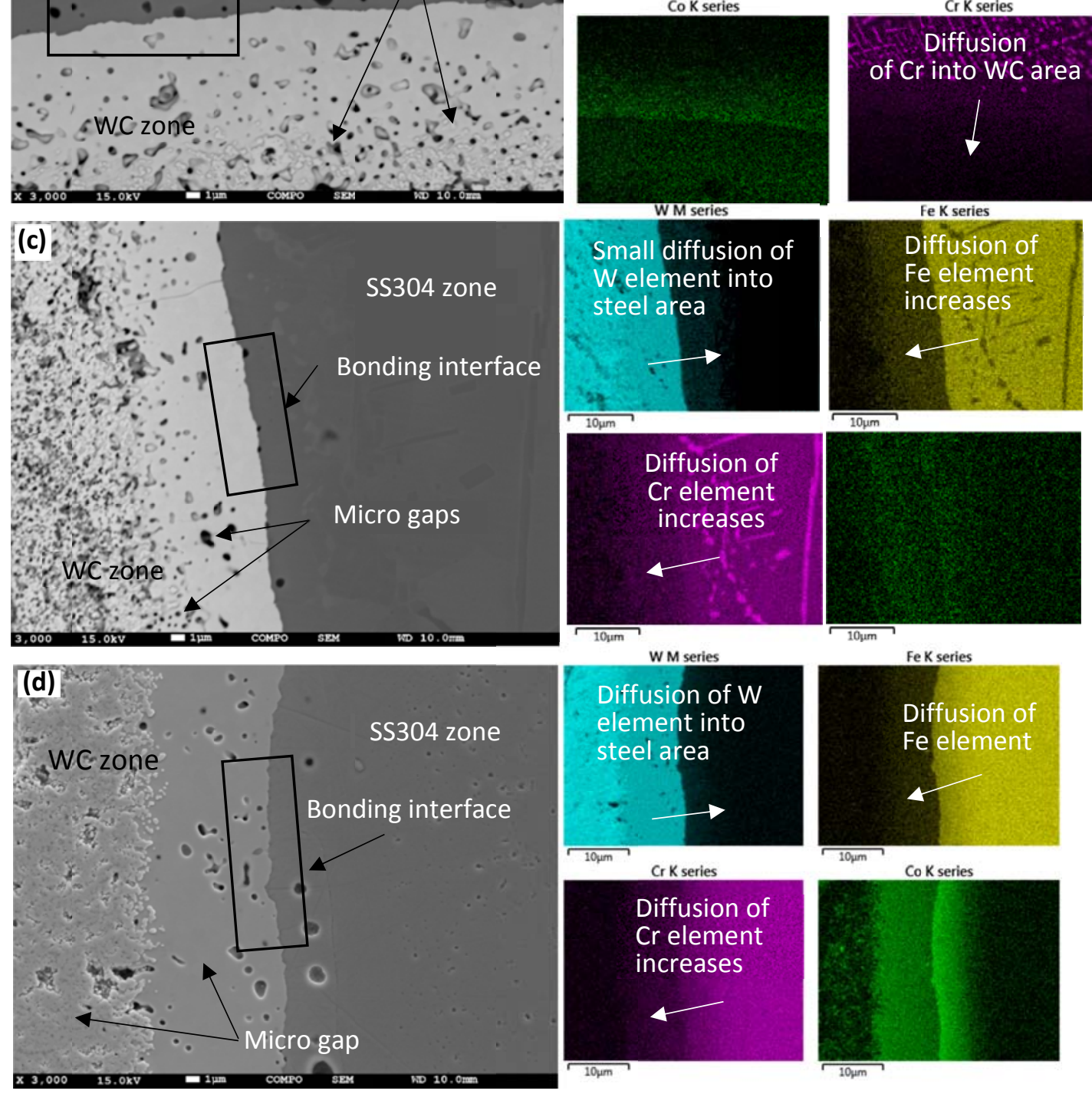
Fig. 9 Bonding interface of WC and SS 304 sintered at (a) $1160^{\circ} \mathrm{C}$, (b) $1180^{\circ} \mathrm{C}$, (c) $1200{ }^{\circ} \mathrm{C}$, and (d) $1220^{\circ} \mathrm{C}$. can be attriputea to the tollowing reasons: 1 ) the Iarge aitrerence or (It petween vv ana re[sb], 4 ) reluctances of $\mathrm{W}$ elements to diffusion as $\mathrm{W}$ element is much heavier than Fe [34], and 3) difference of physical properties e.g. melting temperature; $\left(2800^{\circ} \mathrm{C}\right.$ for $\mathrm{WC}[36]$ and $\sim 1500^{\circ} \mathrm{C}$ for SS $\left.304[37]\right)$. During cooling period, SS 304 starts to shrink faster than WC due to its lower number of CTE values, which causes the generation of cracks at the interface between these two materials. Fig 10 shows micro cracks formed at the WC and SS 304 interface at the temperature of $1220^{\circ} \mathrm{C}$. The left side of the SEM images and EDS maps is WC and the right side is steel. For comparison the images are undertaken with same magnification. Cracks are observed in the regions of interface as well as WC at all temperatures, and formed cracks are characterised by 3 features: long single cracks, cluster of cracks, and cracks in WC region as presented in Fig. 10 (a) - (c), respectively. Long single cracks are formed at the WC and SS 304 interface where Fe element diffusion ends as shown in Fig. 10(a) EDS map. Cluster of cracks are also observed to form at the interface. Both of these type of cracks are formed because of residual stresses that have been developed at the interface due to large mismatch of their thermal coefficient expansion values as described by Yang et al. [12] and Weber et al. [38]. Cracks in WC area that have been formed a bit away from the interface can be because of presence of voids created during the sample preparation. The EDS maps at the corner of BE images, reveal that no element is present in the void of cracks. The presence of cracks significantly decreases the quality of joining interface as well as the bonding strength between WC and SS 304. Crack formation, however, in powdersolid bonding of WC and steels 304 presented in this work, is believed to be minimal considering to that of solidstate bonding. The likely explanation for this is the higher diffusion tendency of powder materials in powder-solid state bonding [39]. In solid state bonding, diffusion of WC particles are reported to be minimum due to high melting temperature and heavier molecular mass compared to steel[40]. On contrary, in powder-solid bonding, the powder molecules of WC can penetrate more easily at lower temperature[41]. This phenomena contribute to the diffusion of both WC into steel and steel into WC, and consequently resulting in the formation of better quality of bonding.
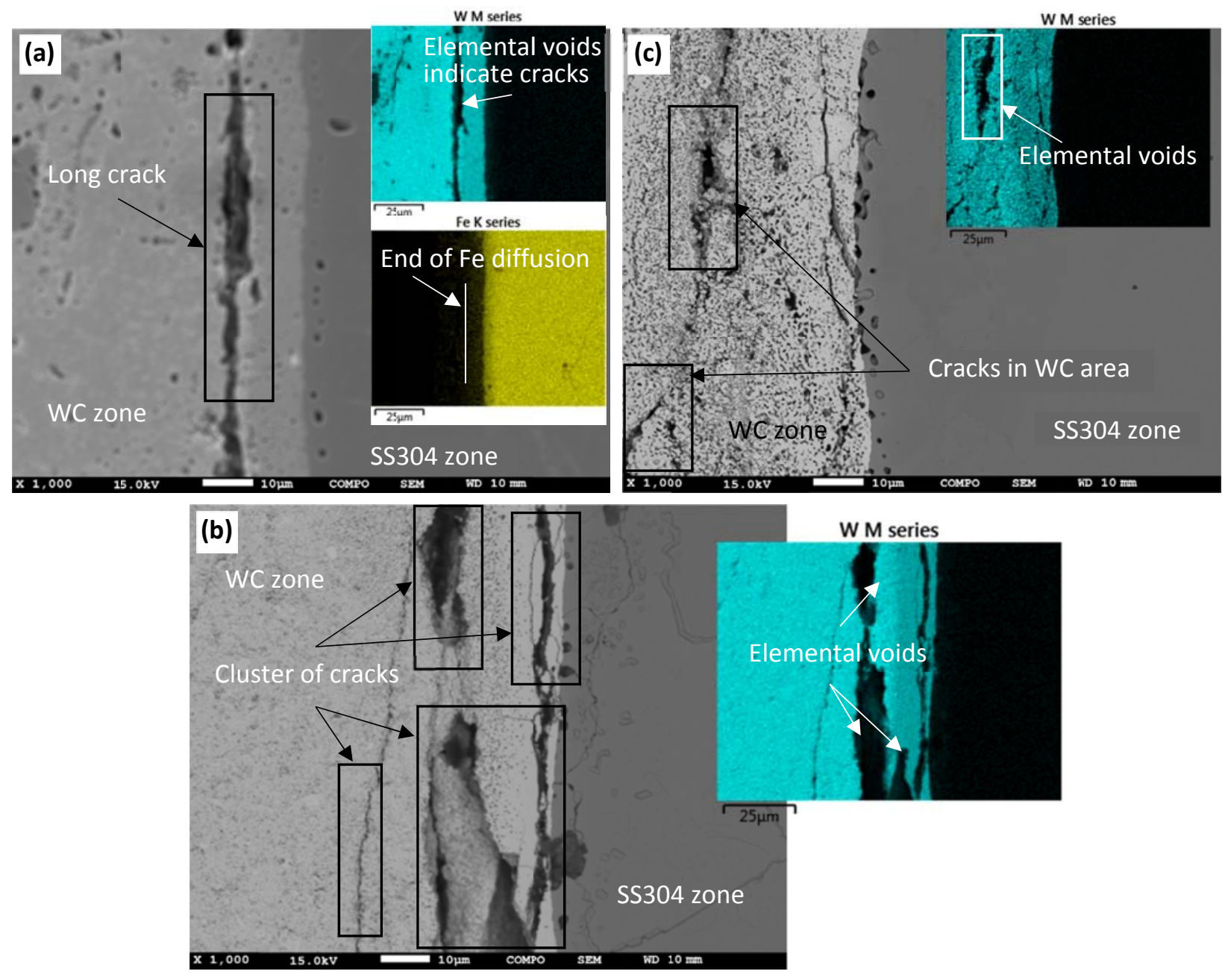
Fig. 10 Cracks formed at the WC and SS 304 interface at $1220^{\circ} \mathrm{C}(\mathrm{a})$ single long crack at the interface,)b) cluster of cracks, and(c) cracks in the WC region

Another important phenomenon observed in this study is the generation of an interface layer at the bonding area. Fig. 11. Shows the interface layers of the samples at $1220^{\circ} \mathrm{C}$ and $1200{ }^{\circ} \mathrm{C}$, in which the left side is WC and the right side is SS 304. The width of these layers varies from a minimum thickness of $6 \mu \mathrm{m}$ to the maximum thickness of $22 \mu \mathrm{m}$. The EDS maps indicate that the diffusion layer is rich in carbon elements. The possible phases thought to be present in this region areFe $\mathrm{W}_{3} \mathrm{C}$ and free carbon. The reaction that may take place can be as follows[42].

$3 \mathrm{Fe}+3 \mathrm{WC} \rightarrow \mathrm{Fe}_{3} \mathrm{~W}_{3} \mathrm{C}+2 \mathrm{C}$

As can be seen in EDS mapping, that enormous carbon elements have deposited in this area. The abundance of free carbon can be generated from Eq. 2 as well as following reaction[43].

$2 \mathrm{Co}_{3} \mathrm{~W}_{3} \mathrm{C}+\mathrm{CO} \rightarrow \mathrm{Co}_{7} \mathrm{~W}_{6}+2 \mathrm{C}$
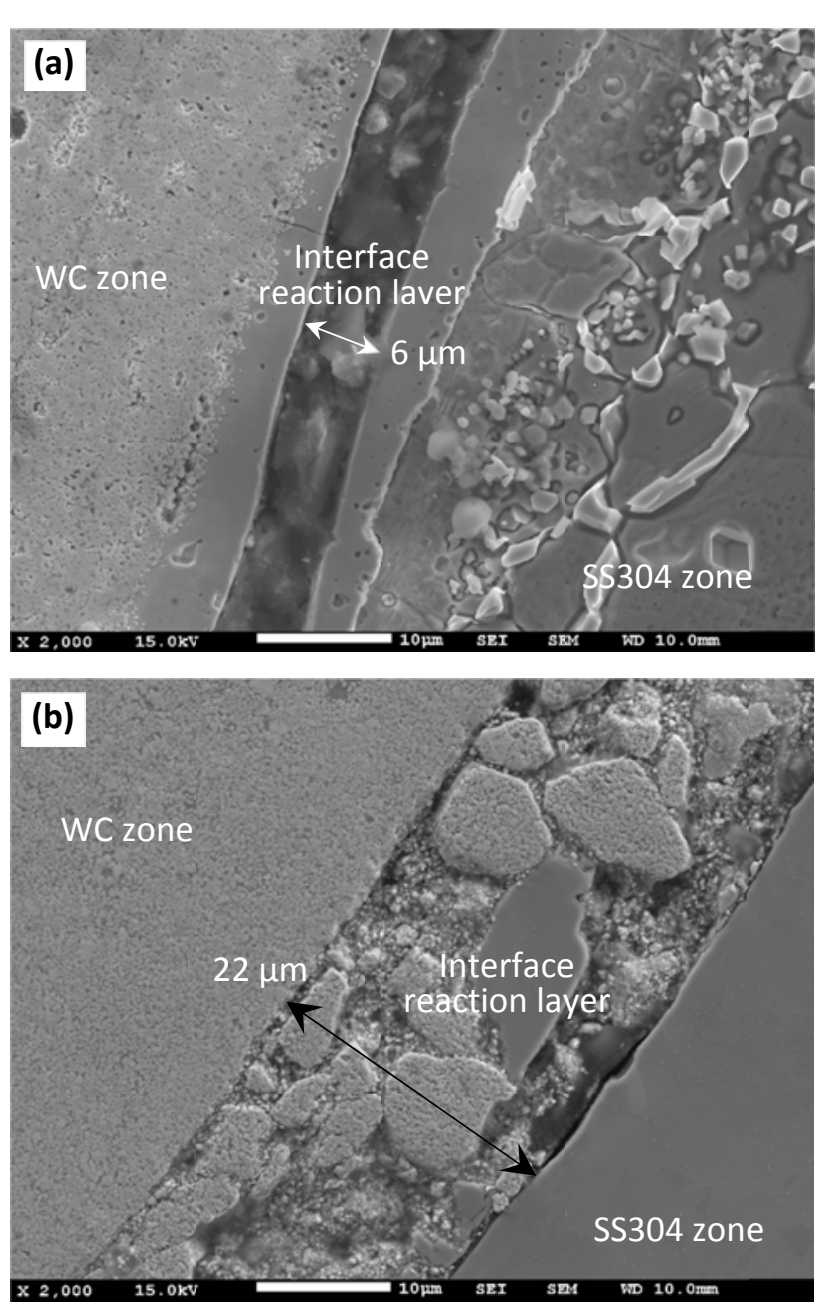
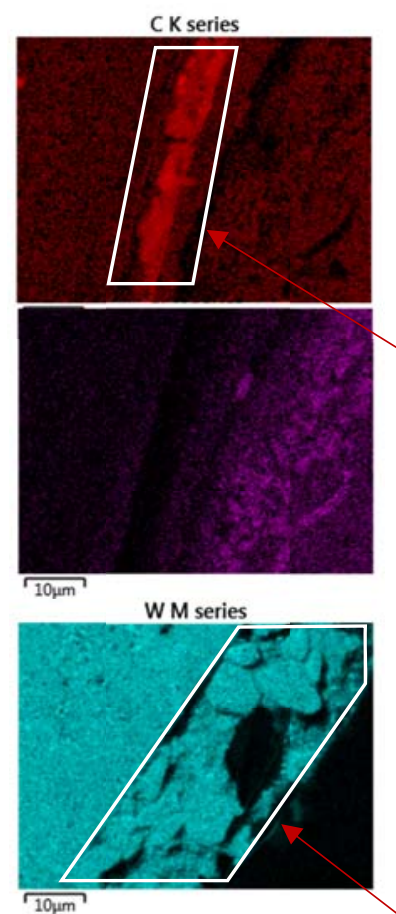

Fe K series

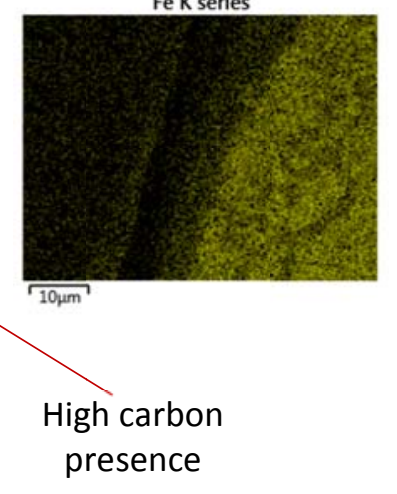

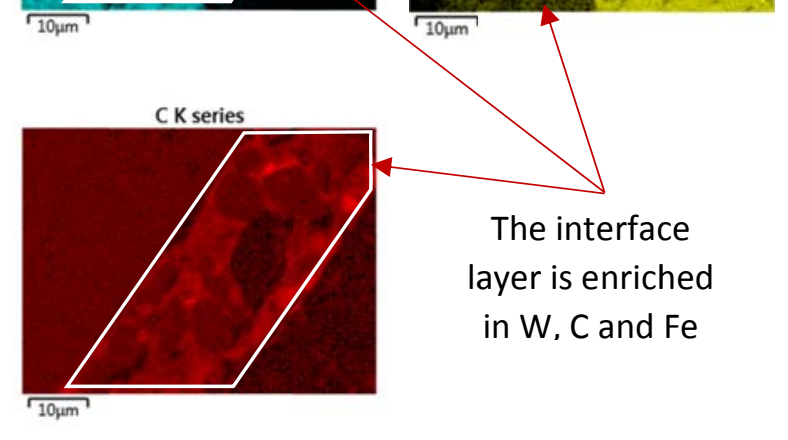


Fig. 11 Interface layers of the samples sintered at (a) $1220^{\circ} \mathrm{C}$, and(b) $1200^{\circ} \mathrm{C}$.

\subsection{XRD phase analysis}

In the current study, XRD analysis was conducted in order to determine the various phases present in the composite bimetal of WC and solid SS304. Fig. 12 shows a typical spectrum of the bimetal sintered at $1220{ }^{\circ} \mathrm{C}$. The XRD spectrum specifies the existence of $W_{2} C$ (ICCD card: 20-1315), pertaining to $2 \theta$ values $39.56^{\circ}$ and $81.25^{\circ}$, which is associated to the possible decarburization of $\mathrm{WC}[44]$. The decomposition of $\mathrm{WC}$ and formation of $\mathrm{W}_{2} \mathrm{C}$ can be attributed by following two equations which form in the temperature range of $1000^{\circ} \mathrm{C}$ to $1300{ }^{\circ} \mathrm{C}$ [45].

$W C \rightarrow W+C$

$2 W+C \rightarrow W_{2} C$

The XRD spectrum indicates the existence of ferrochrome ( $\mathrm{FeCr}$ ) which can be attributed to the raw component of SS304. The spectrum also illustrates the presence ofFe ${ }_{3} \mathrm{~W}_{3} \mathrm{C}$ (ICCD card: 23-1128) pertaining to $2 \theta$ values $64.2^{\circ}$, $65.62^{\circ}, 69.13^{\circ}$ and $77.13^{\circ}$. This can be attributed to the reaction among Fe, $\mathrm{W}$ and $\mathrm{C}$ as mentioned in Eq. (2). The existence of $\mathrm{CO}_{3} \mathrm{~W}_{3} \mathrm{C}$ phase (ICCD card: $24-1125$ ), corresponding to $2 \theta$ values $42.42^{\circ}, 83.33^{\circ}$ and $98.95^{\circ}$, can be described as the diffusion of Co molecules into WC particles at high temperature. The possible reaction that could take place can be presented by Eq. (6)[46]:

$3 \mathrm{WC}+3 \mathrm{Co}+\mathrm{O}_{2} \rightarrow \mathrm{Co}_{3} \mathrm{~W}_{3} \mathrm{C}+2 \mathrm{C}$

The formation of phase $\mathrm{CO}_{7} \mathrm{~W}_{6}$ (ICCD file: $02-1091$ ), corresponding to $2 \theta$ values $47.56^{\circ}, 57.25^{\circ}, 73.01^{\circ}$ and $77.09^{\circ}$, is attributed by the reaction between $\mathrm{CO}_{3} \mathrm{~W}_{3} \mathrm{C}$ and $\mathrm{CO}$. The reaction formula is presented in Eq. 3 [43]. The XRD spectrum also indicates the presence of $\mathrm{Al}_{5} \mathrm{CO}_{2}$ phase (ICCD card: 03-1080), corresponding $2 \theta$ values $29.14^{\circ}, 40.61^{\circ}$ and $93.13^{\circ}$. The decomposition of $\mathrm{Al}_{5} \mathrm{CO}_{2}$ can be attributed to the following equation [47]:

$\mathrm{AlCo}+4 \mathrm{Al}+\mathrm{Co}=\mathrm{Al}_{5} \mathrm{CO}_{2}$

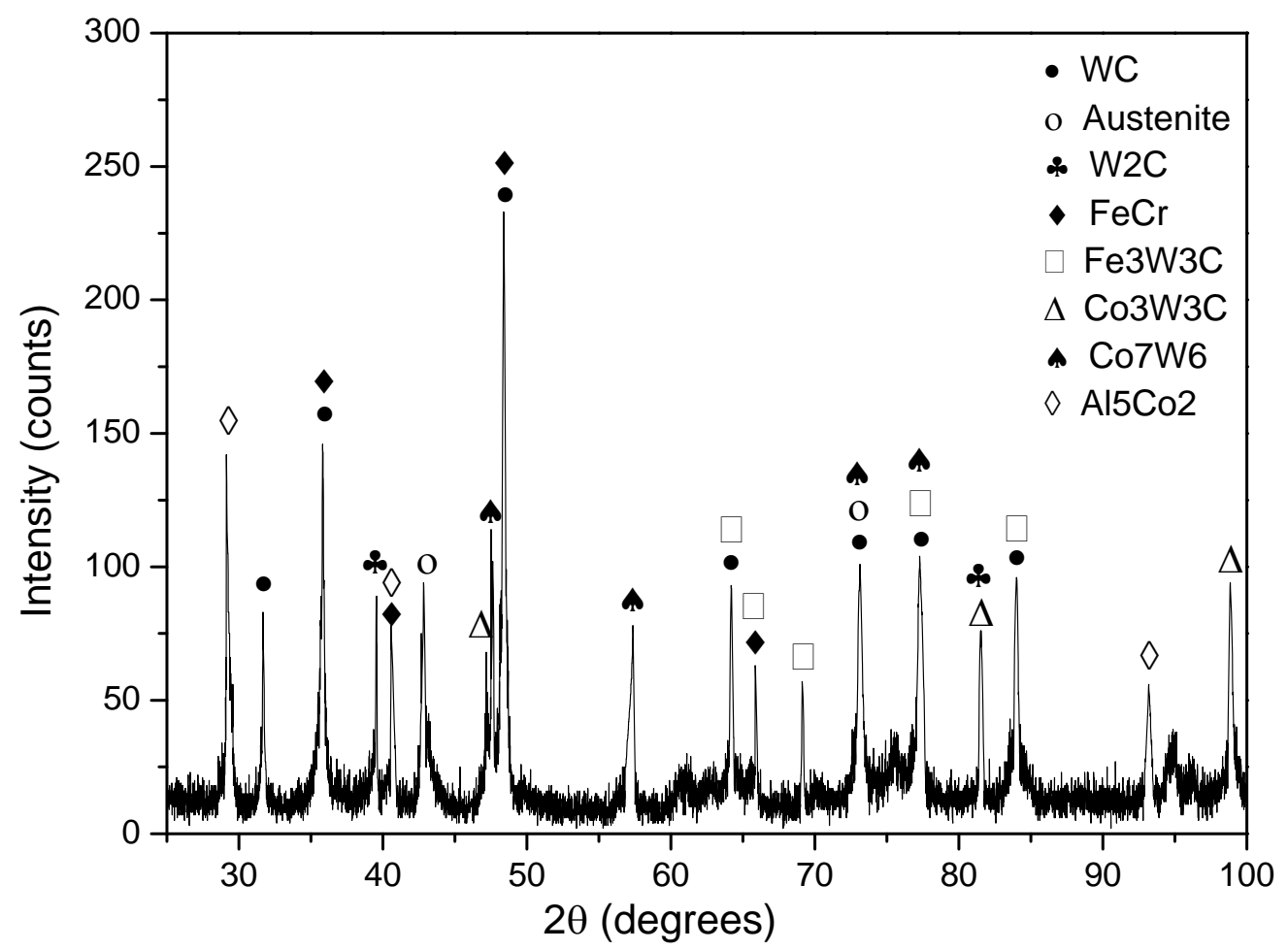

Fig. 12 XRD spectrum of the composite bimetal sintered at $1220^{\circ} \mathrm{C}$. 


\subsection{Evaluation of mechanical properties}

Mechanical properties of the fabricated composite bimetal WC and SS3 04 have been evaluated by means of micro hardness test and bonding shear strength test. Fig. 13(a) and (b) show the indentation points and the microhardness profiles attained across the interface of composite bimetal respectively. The left and right part of the curve present the hardness of WC, and the middle part for SS304. It can be seen that the hardness of WC shows an increasing trend with the increase of temperature. As discussed in earlier section, since the density of sintered WC increases with the increase of temperature, this contributes to the increase of hardness. This finding is in line with outcome investigated by Srivatsan et al. [48]. They have shown that hardness of WC increases with an increase of density. The average hardness values of WC achieved at 1160, 1180, 1200 and $1220^{\circ} \mathrm{C}$ are $1255,1705,1810.5$ and $1971 \mathrm{HV}$, respectively. The hardness of SS304, however, remains similar at all temperatures as indicated in Fig. 13(b). The reasons of no significant change in hardness of SS 304 are the nonappearance of any visible phase transformation due to temperature variation and resemblance of grain sizes of the specimens obtained at different temperatures.
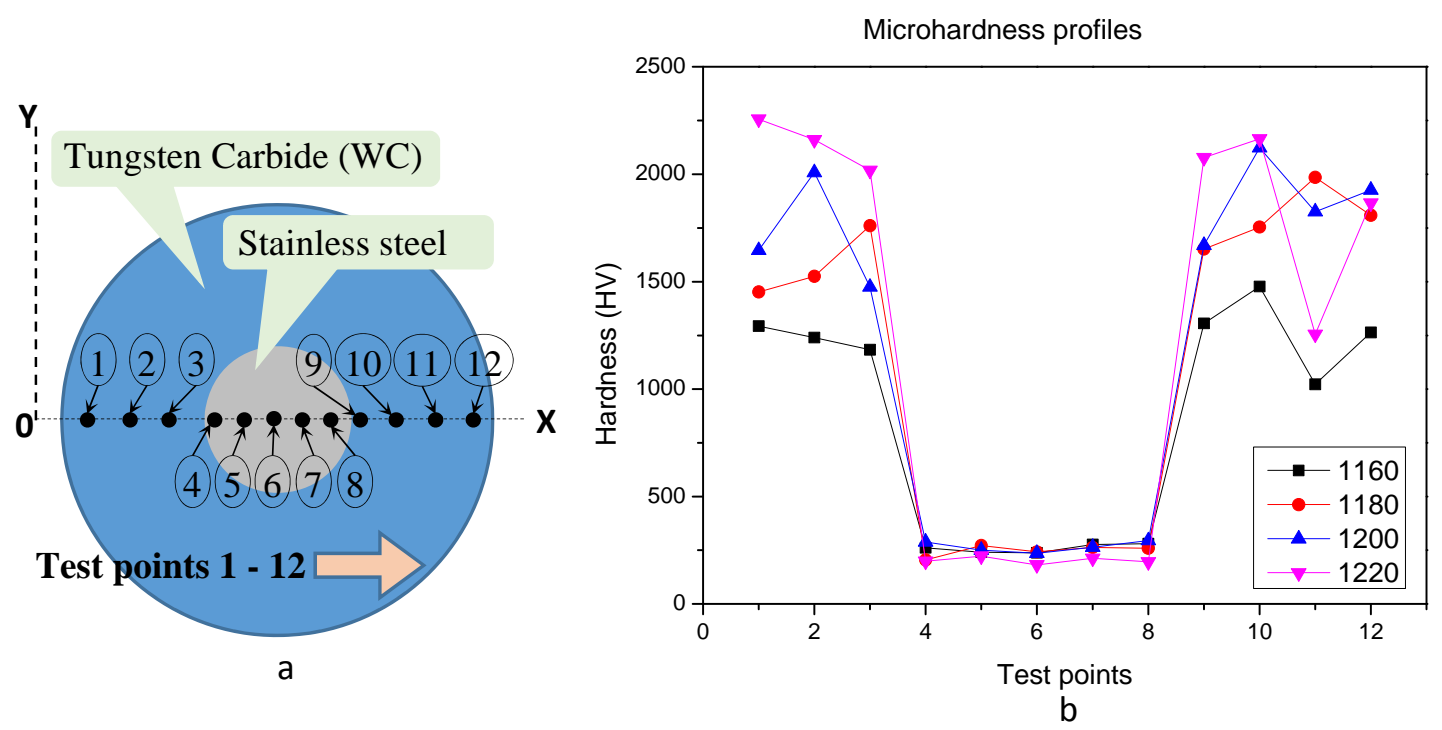

Fig. 13Microhardness profiles of the composite bimetal:(a) schematic diagram showing the measurement points, and (b) microhardness profiles taken at different temperatures.

To investigate the bonding strength at the interface, a tailor made apparatus was employed as mentioned in Fig. 5 (b). As depicted in the figure, the anvil goes from left to right until the steel part fall off. The micro tensile machine, equipped with a high precision load cell, continuously records the force provided by the anvil against the time. The results show that the maximum bonding shear strength is obtained at the sintering temperature of $1220^{\circ} \mathrm{C}$. The result is shown in Fig. 14.It can be seen from the figure that the force increases progressively with the time until it reaches the critical value as denoted by the red dotted line. This is the point where the bond between WC and SS 304 can sustain. Beyond this point, when force continues to apply, shear failure of the bonded area happens and the value of force starts to reduce before it reaches the ultimate fracture point. The ultimate fracture occurs when the steel part falls off the bonding as shown in right side of Fig. 14. The maximum force that the bond can sustain, reported to be $379 \mathrm{~N}$. The ultimate fracture occurs at $268 \mathrm{~N}$. Based on Eq. (1), the force is converted to calculate the bonding shear strength as reported by [28]. The maximum value of bonding shear strength achieved is $172.27 \mathrm{MPa}$. 


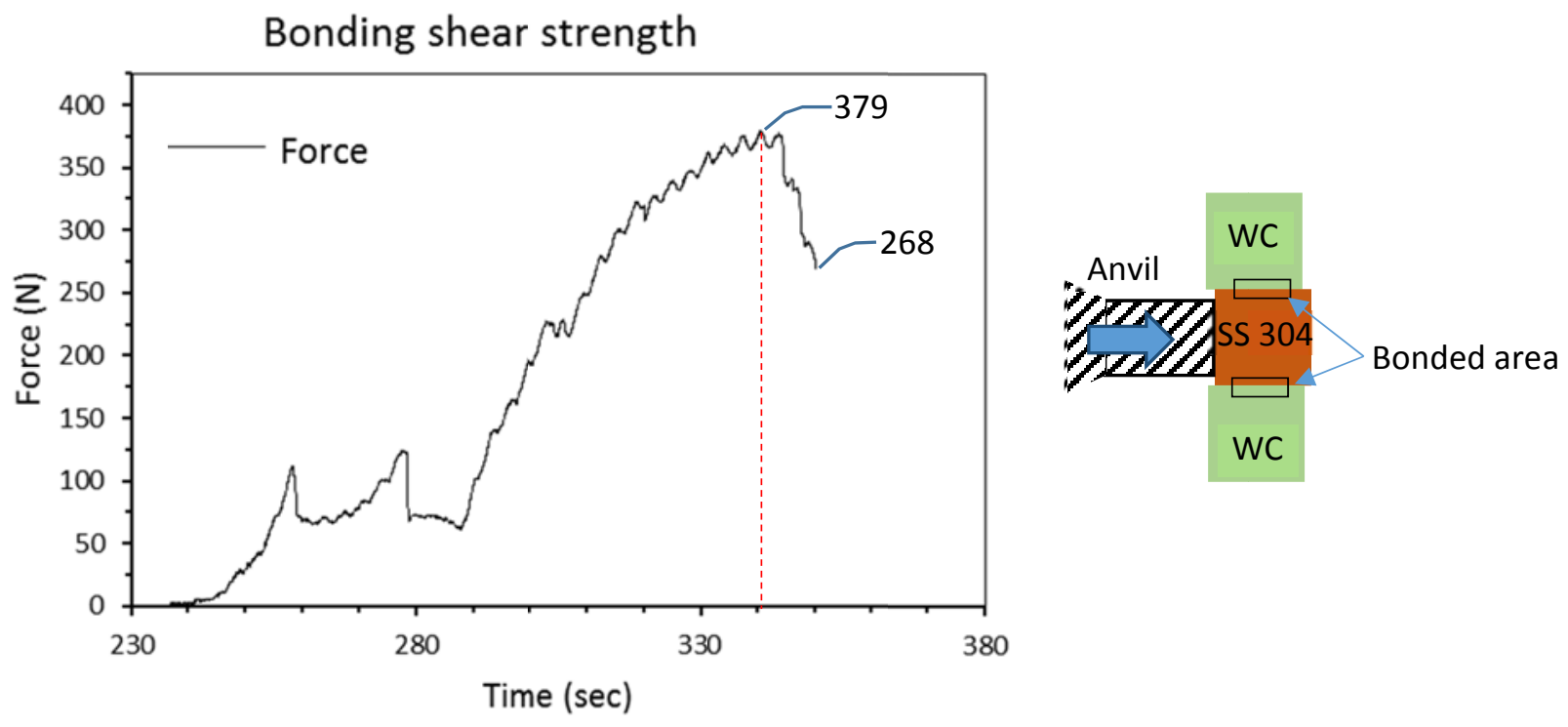

Fig. 14 Determination of bonding shear strength in micro tensile test.

\section{Conclusion:}

In this study, a novel technique termed as HCDB was demonstrated, to examine the bonding characteristics between WC and SS 304. A powder-solid sintering and bonding route was implemented with the aims of enhancing inter-particle diffusion and improvingthe quality of bonding between them. HCDB showed the possibility of manufacturing diffusion based composite bimetal with improved quality of bonding. Ultrafine WC powder and SS304 wire were used as outer and inner materials respectively. The experiment was conducted at different temperatures ranging from $1160^{\circ} \mathrm{C}$ to $1220^{\circ} \mathrm{C}$ while the pressure and time were kept constant at $160 \mathrm{MPa}$ and 20 mins respectively. The microstructure, phase formation and mechanical properties of composite bimetal have been analysed. WC powder was completely solidified; however, the microstructure revealed the presence of micro gaps due to inadequate initial green density. The amount of micro gaps reduced with the increment of temperature. The density obtained varied from 12.29 to $12.71 \mathrm{~g} / \mathrm{cm}^{3}$ which were 81.99 to $84.40 \%$ compared to theoretical ones. The bonding interface was characterised by three phenomena, i.e. regions of good bonding, appearance of micro cracks and formation of interface layer. The phases formed during sintering and bonding were examined by XRD spectrum and the corresponding possible reactions were illustrated. The mechanical properties of the bimetal indicated the achievement of high hardness of the WC and good bonding between WC and steel. The maximum hardness of WC and bonding shear strength obtained ware $1971 \mathrm{HV}$ and $172 \mathrm{MPa}$, respectively. Further research is necessary to optimise the parameters for better sintering performance and high quality of bonding. In the applications where high hardness and high strength are necessary, this fabricated composite bimetal has substantial potentials to be used.

\section{Acknowledgement}

The authors would like to thank the Australian Research Council (ARC) for its financial support for the current study. We also acknowledge the use of facilities within the UOW Electron Microscopy Centre. 


\section{References:}

1. Kumar, V., et al., An analysis of grain boundaries and grain growth in cemented tungsten carbide using orientation imaging microscopy. Metallurgical and materials transactions A, 2006. 37(3): p. 599-607.

2. Goren-Muginstein, G., S. Berger, and A. Rosen, Sintering study of nanocrystalline tungsten carbide powders. Nanostructured materials, 1998. 10(5): p. 795-804.

3. Matějiček, J., et al., W-steel and W-WC-steel composites and FGMs produced by hot pressing. Fusion Engineering and Design, 2015. 100(Supplement C): p. 364-370.

4. Norajitra, P., et al., Development of a helium-cooled divertor: material choice and technological studies. Journal of Nuclear Materials, 2007. 367: p. 1416-1421.

5. Basuki, W.W. and J. Aktaa, Diffusion bonding between W and EUROFER97 using V interlayer. Journal of Nuclear Materials, 2012. 429(1): p. 335-340.

6. Basuki, W. and J. Aktaa, Investigation of tungsten/EUROFER97 diffusion bonding using Nb interlayer. Fusion Engineering and Design, 2011. 86(9): p. 2585-2588.

7. Rosiński, M., et al., W/steel joint fabrication using the pulse plasma sintering (PPS) method. Fusion Engineering and Design, 2011. 86(9): p. 2573-2576.

8. Kalin, B., et al., Development of brazing foils to join monocrystalline tungsten alloys with ODS-EUROFER steel. Journal of nuclear materials, 2007. 367: p. 1218-1222.

9. Greuner, H., et al., Vacuum plasma-sprayed tungsten on EUROFER and 316L: Results of characterisation and thermal loading tests. Fusion engineering and design, 2005. 75: p. 333-338.

10. Hirose, T., et al., Joining technologies of reduced activation ferritic/martensitic steel for blanket fabrication. Fusion Engineering and Design, 2006. 81(1): p. 645-651.

11. Rosinski, M., et al., W/Cu composites produced by pulse plasma sintering technique (PPS). Fusion Engineering and Design, 2007. 82(15): p. 2621-2626.

12. Yang, Z.-h., et al., Tungsten/steel diffusion bonding using $\mathrm{Cu} / \mathrm{W}-\mathrm{Ni} / \mathrm{Ni}$ multi-interlayer. Transactions of Nonferrous Metals Society of China, 2014. 24(8): p. 2554-2558.

13. Zhong, Z., et al., Microstructure and mechanical properties of diffusion bonded joints between tungsten and F82H steel using a titanium interlayer. Journal of Alloys and Compounds, 2010. 489(2): p. 545-551.

14. Zhong, Z., T. Hinoki, and A. Kohyama, Effect of holding time on the microstructure and strength of tungsten/ferritic steel joints diffusion bonded with a nickel interlayer. Materials Science and Engineering: A, 2009. 518(1): p. 167-173.

15. Feng, K., et al., Investigation on diffusion bonding of functionally graded WC-Co/Ni composite and stainless steel. Materials \& Design, 2013. 46: p. 622-626.

16. Carroll, D., Sintering and microstructural development in WC/Co-based alloys made with superfine WC powder. International Journal of Refractory Metals and Hard Materials, 1999. 17(1): p. 123-132.

17. Fang, Z. and J.W. Eason, Study of nanostructured WC-Co composites. International Journal of Refractory Metals and Hard Materials, 1995. 13(5): p. 297-303.

18. Azcona, l., et al., Hot isostatic pressing of ultrafine tungsten carbide-cobalt hardmetals. Journal of materials science, 2002. 37(19): p. 4189-4195.

19. Sivaprahasam, D., S. Chandrasekar, and R. Sundaresan, Microstructure and mechanical properties of nanocrystalline WC-12Co consolidated by spark plasma sintering. International Journal of Refractory Metals and Hard Materials, 2007. 25(2): p. 144-152.

20. Maizza, G., et al., Relation between microstructure, properties and spark plasma sintering (SPS) parameters of pure ultrafine WC powder. Science and Technology of Advanced Materials, 2007. 8(7): p. 644-654.

21. Michalski, A. and D. Siemiaszko, Nanocrystalline cemented carbides sintered by the pulse plasma method. International Journal of Refractory Metals and Hard Materials, 2007. 25(2): p. 153-158.

22. Kim, H.C., et al., Fabrication of WC-8wt.\% Co hard materials by two rapid sintering processes. International Journal of Refractory Metals and Hard Materials, 2007. 25(4): p. 336-340.

23. Dubensky, E.M. and R.T. Nilsson, Dense fine grained monotungsten carbide-transition metal cemented carbide body and preparation thereof. 1998, Google Patents. 
24. Fang, Z.Z., et al., Synthesis, sintering, and mechanical properties of nanocrystalline cemented tungsten carbide-a review. International Journal of Refractory Metals and Hard Materials, 2009. 27(2): p. 288-299.

25. Groza, J. and A. Zavaliangos, Nanostructured bulk solids by field activated sintering. Rev. Adv. Mater. Sci, 2003. 5(1): p. 24-33.

26. Dehghan-Manshadi, A., et al. Resistance Heated Pressing (RHP): A novel technique for fabrication of titanium alloys. in Key Engineering Materials. 2012. Trans Tech Publ.

27. Maki, S., Y. Harada, and K. Mori, Application of resistance sintering technique to fabrication of metal matrix composite. Journal of Materials Processing Technology, 2001. 119(1): p. 210-215.

28. Gao, X., et al., Effects of temperature and strain rate on microstructure and mechanical properties of high chromium cast iron/low carbon steel bimetal prepared by hot diffusion-compression bonding. Materials \& Design, 2014. 63: p. 650-657.

29. Inc., D.S. Offering versatility and performance for today's demanding research and production applications. The Gleeble 3500 Thermal System 2017; Available from: https://www.gleeble.com/products/gleeble3500.html.

30. Maheshwari, P., Z.Z. Fang, and H.Y. Sohn, Early-stage sintering densification and grain growth of nanosized WC-Co powders. International Journal of Powder Metallurgy (Princeton, New Jersey), 2007. 43(2): p. 41-47.

31. Wang, X., Z.Z. Fang, and H.Y. Sohn, Grain growth during the early stage of sintering of nanosized WC-Co powder. International Journal of Refractory Metals and Hard Materials, 2008. 26(3): p. 232-241.

32. Białobrzeska, B., Ł. Konat, and R. Jasiński, The Influence of Austenite Grain Size on the Mechanical Properties of Low-Alloy Steel with Boron. Metals, 2017. 7(1): p. 26.

33. Sun, L., C.-C. Jia, and M. Xian, A research on the grain growth of WC-Co cemented carbide. International Journal of Refractory Metals and Hard Materials, 2007. 25(2): p. 121-124.

34. Pelleg, J., Diffusion in Ceramics. Solid Mechanics and Its Applications. Vol. 221. 2015.

35. Cai, Q., et al., Diffusion brazing of tungsten and steel using Ti-Ni liquid phase forming interlayer. Fusion Engineering and Design, 2015. 91: p. 67-72.

36. Wikipedia, T.F.E. Tungsten carbide. Available from: https://en.wikipedia.org/wiki/Tungsten carbide.

37. Materials, A. Stainless Steel - Grade 304 (UNS S30400). Available from:

https://www.azom.com/properties.aspx?ArticlelD=965.

38. Weber, T. and J. Aktaa, Numerical assessment of functionally graded tungsten/steel joints for divertor applications. Fusion Engineering and Design, 2011. 86(2): p. 220-226.

39. Fillabi, M.G., A. Simchi, and A.H. Kokabi, Effect of iron particle size on the diffusion bonding of $\mathrm{Fe}-5 \% \mathrm{Cu}$ powder compact to wrought carbon steels. Materials \& Design, 2008. 29(2): p. 411-417.

40. Lemus-Ruiz, J., A.L. Salas-Villaseñor, and O. Flores. Joining of WC-Co to Ni by direct diffusion bonding. in Advanced Materials Research. 2009. Trans Tech Publ.

41. F, B.J., et al., Powder for diffusion bonding of superalloy members. 1972, Google Patents.

42. Telmenbayar, L. and J. Temuujin, Preparation of tungsten carbide from mixtures of natural wolframite and carbon-containing solid fuels with assistance of mechanical activation. Journal of Ceramic Processing Research, 2016. 17(5): p. 489-493.

43. Babutina, T.E., et al., Preparation of hard alloy WC and WC-Co mixtures with reduction and carbidizing treatment of oxidized tungsten containing scrap. Powder Metallurgy and Metal Ceramics, 2004. 43(3-4): p. 111-116.

44. Lassner, E. and W.D. Schubert, Tungsten: Properties, Chemistry, Technology of the Element, Alloys, and Chemical Compounds. 2012: Springer US.

45. Jehn, H., et al., W Tungsten: Supplement Volume A 5 b Metal, Chemical Reactions with Nonmetals Nitrogen to Arsenic. 2013: Springer Berlin Heidelberg.

46. Guilemany, J.M., et al., Characterization of the W2C phase formed during the high velocity oxygen fuel spraying of a WC +12 pct Co powder. Metallurgical and Materials Transactions A, 1999. 30(8): p. 1913-1921.

47. Palcut, M., et al., Corrosion behaviour of Al-29at\% Co alloy in aqueous NaCl. Corrosion Science, 2013. 75: p. 461-466.

48. Srivatsan, T.S., et al., An investigation of the influence of powder particle size on microstructure and hardness of bulk samples of tungsten carbide. Powder Technology, 2002. 122(1): p. 54-60. 